\title{
Editorial: Consequences of lodine Deficiency in Pregnancy
}

\author{
Sun Y. Lee* \\ Section of Endocrinology, Diabetes, and Nutrition, Boston University School of Medicine, Boston, MA, United States
}

Keywords: iodine, pregnancy, iodine deficiency, iodine deficiency in pregnancy, hypothyroidism in pregnancy

Editorial on the Research Topic

Consequences of Iodine Deficiency in Pregnancy

\section{INTRODUCTION}

Iodine is an essential micronutrient for thyroid hormone synthesis. Adequate thyroid hormone is critical for normal fetal development. As the fetal thyroid gland does not mature until midgestation, the fetus depends solely on maternal thyroid hormone crossing the placenta during early stages of pregnancy (1). Maternal overt hypothyroidism is associated with adverse pregnancy and child developmental outcomes $(2,3)$. However, the effects of maternal subclinical hypothyroidism have been debated. In this Research Topic, Chen et al. explored potential associations between maternal thyroid function and birth outcomes in 8,985 Chinese mother-child pairs. Serum thyroid stimulating hormone (TSH), free thyroxine (FT4), and thyroid peroxidase (TPO) antibody levels were measured. Rates of cesarean section, preterm birth, neonatal hyperbilirubinemia, and low birth weight (LBW) were assessed. Children born to mothers with TSH $>4.0 \mathrm{mIU} / \mathrm{L}$ had a two-fold higher risk of LBW compared to those born to mothers with TSH $0.1-2.5 \mathrm{mIU} / \mathrm{L}$, regardless of TPO antibody status. This finding is in line with previous studies showing adverse effects of maternal subclinical hypothyroidism on fetal growth (4). However, there were no significant associations between maternal subclinical hypothyroidism and risks of other birth outcomes, in contrast to the increased risk of preterm birth seen in several previous studies $(5,6)$. Conflicting reports regarding the effects of maternal subclinical hypothyroidism on pregnancy outcomes may be due to variability in timing of thyroid function measurements, iodine status of the study populations, and assessment of TPO antibody status among studies.

Given the importance of adequate thyroid hormone, adequate maternal iodine nutrition is essential during pregnancy. There is an increased demand for iodine in pregnancy due to increased thyroid hormone production, increased urinary iodine losses, and transplacental transport of iodine for fetal thyroid hormone synthesis (7). Consequently, the World Health Organization (WHO) recommends a higher iodine intake of $250 \mu \mathrm{g}$ /day in pregnant women, compared to $150 \mu \mathrm{g} / \mathrm{day}$ in non-pregnant adults (8). Despite global efforts to implement salt iodization by international organizations such as the Iodine Global Network (IGN), UNICEF, and WHO, iodine deficiency remains a leading cause of maternal hypothyroidism worldwide. Recent data from IGN showed that pregnant women had inadequate iodine status in 23 out of 34 countries assessed (9), and 35 million newborns are estimated to be unprotected from adverse consequences of iodine deficiency worldwide. In this Research Topic, Toloza et al. reviewed consequences of severe iodine deficiency in pregnancy. Maternal severe iodine deficiency is associated with adverse pregnancy outcomes such as miscarriage, stillbirth, neonatal mortality, and growth retardation. It also affects 
neonatal and offspring development since thyroid hormone is essential for normal brain development $(10,11)$. As discussed in the review by Toloza et al., the effects of maternal severe iodine deficiency on offspring neurocognitive development are most dramatically demonstrated by cretinism and its eradication with iodine supplementation $(12,13)$.

However, the effects of mild-to-moderate iodine deficiency in pregnancy are more variable. Some studies have shown increased risks of miscarriage (14), preterm labor (15-17), and LBW (15, 16), and impaired language (18) and fine motor development (19) in children of mild-to-moderately iodine deficient mothers. In contrast, other studies reported no significant association between maternal iodine status and adverse pregnancy outcomes (20) or verbal skills in children (21). In this Research Topic, Schiller et al. assessed iodine status and thyroid function of 100 healthy Israeli pregnant women in their first trimester. Women in this study had moderate iodine deficiency with a median urinary iodine concentration (UIC) of $49 \mu \mathrm{g} / \mathrm{L}$. Iodinecontaining supplement use was strongly correlated with UIC, although $53 \%$ of women taking iodine-containing supplements still had UIC $<100 \mu \mathrm{g} / \mathrm{L}$. However, there were no significant associations between maternal UIC in the first trimester and maternal or neonatal thyroid hormone levels. There were no significant associations between maternal UIC levels and gestational age at birth or birth weight, similar to a previous U.K. study (20).

There are only a few studies assessing the impact of maternal iodine supplementation on pregnancy or childhood developmental outcomes. Some studies showed higher developmental scores in children of women with iodine supplementation, while others did not $(22,23)$. In this issue, Verhagen et al. assessed the effects of iodine supplementation on maternal thyroid function and child development in a mildly iodine deficient population. A total of 514 Thai pregnant women were randomized to either $200 \mu \mathrm{g} /$ day of iodine or placebo from the first trimester to delivery. The median UIC at recruitment was $112 \mu \mathrm{g} / \mathrm{L}$, indicating mild iodine deficiency. Iodine-treated mothers had a slightly greater decrease in FT4 levels compared to placebo-treated mothers, although all remained within normal range. At 5.7 years of age, there were no significant differences in developmental assessment scores between children in the iodine group and children in the placebo group. It is notable that mothers in placebo group also achieved iodine sufficiency in the second and third trimesters, which may have contributed to the lack of treatment effect. Evidence regarding the benefit of

\section{REFERENCES}

1. Burrow GN, Fisher DA, Larsen PR. Maternal and Fetal Thyroid Function. N Engl J Med (1994) 331:1072-8. doi: 10.1056/NEJM199410203311608

2. Männistö T, Mendola P, Grewal J, Xie Y, Chen Z, Laughon SK. Thyroid Diseases and Adverse Pregnancy Outcomes in a Contemporary US Cohort. J Clin Endocrinol Metab (2013) 98:2725-33. doi: 10.1210/ jc.2012-4233

3. Haddow JE, Palomaki GE, Allan WC, Williams JR, Knight GJ, Gagnon J, et al. Maternal Thyroid Deficiency During Pregnancy and Subsequent Neuropsychological Development of the Child. N Engl J Med (1999) 341:549-55. doi: 10.1056/NEJM199908193410801 maternal iodine supplementation in pregnancy is currently limited by the variable exposure time during pregnancy, with initiation of iodine supplementation later in pregnancy in some cases, and lack of significant differences in iodine status of pregnant women between iodine supplemented and control groups in some available studies.

This Research Topic explored topics related to iodine nutrition in pregnancy. Adequate thyroid hormone and iodine nutrition are important in pregnancy, as evidenced by adverse effects of severe iodine deficiency on pregnancy and child neurodevelopmental outcomes. However, the effects of mildto-moderate iodine deficiency in pregnancy are less clear. A few intervention trials on potential benefits of maternal iodine supplementation in pregnancy have shown a lack of significant benefit, but these trials have had several methodologic limitations. Given the currently available evidence, many societies including the American Thyroid Association, the European Thyroid association, and the Endocrine Society recommend supplementation with $150 \mu \mathrm{g} /$ day of iodine in women who are planning to become pregnant or are pregnant. Still, larger cohort studies and interventional trials are needed to further elucidate the effects of mild-to-moderate maternal iodine deficiency in pregnancy and the potential impact of iodine supplementation.

\section{AUTHOR CONTRIBUTIONS}

The author confirms being the sole contributor of this work and has approved it for publication.

\section{FUNDING}

SYL is supported in part by NIH 1K23ES028736-01A1 and Boston University School of Medicine Department of Medicine Career Investment Award.

\section{ACKNOWLEDGMENTS}

I thank my co-topic editors, John H Lazarus, Elizabeth N. Pearce, and Eduardo Andres Pretell for their expertise and effort in completing this Research Topic.

4. Derakhshan A, Peeters RP, Taylor PN, Bliddal S, Carty DM, Meems M, et al. Association of Maternal Thyroid Function With Birthweight: A Systematic Review and Individual-Participant Data Meta-Analysis. Lancet Diabetes Endocrinol (2020) 8:501-10. doi: 10.1016/S2213-8587(20)30061-9

5. Lee SY, Cabral HJ, Aschengrau A, Pearce EN. Associations Between Maternal Thyroid Function in Pregnancy and Obstetric and Perinatal Outcomes. J Clin Endocrinol Metab (2020) 105:e2015-23. doi: 10.1210/clinem/dgz275

6. Consortium on Thyroid and Pregnancy-Study Group on Preterm Birth, Korevaar TIM, Derakhshan A, Taylor PN, Meima M, Chen L, et al. Association of Thyroid Function Test Abnormalities and Thyroid Autoimmunity With Preterm Birth: A Systematic Review and MetaAnalysis. JAMA (2019) 322:632-41. doi: 10.1001/jama.2019.10931 
7. Leung AM, Pearce EN, Braverman LE. Iodine Nutrition in Pregnancy and Lactation. Endocrinol Metab Clin North Am (2011) 40:765-77. doi: 10.1016/ j.ecl.2011.08.001

8. WHO Secretariat, Andersson M, de Benoist B, Delange F, Zupan J. Prevention and Control of Iodine Deficiency in Pregnant and Lactating Women and in Children Less Than 2-Years-Old: Conclusions and Recommendations of the Technical Consultation. Public Health Nutr (2007) 10:1606-11. doi: 10.1017/ S1368980007361004

9. The Iodine Global Network. Global Scorecard of Iodine Nutrition in 2017 in the General Population Based on School-Age Children (SAC) With Additional Data for Pregnant Women $(P W)$. Available at: https://www.ign.org/cm_data/IGN_Global_ Scorecard_AllPop_and_PW_May20171.pdf (Accessed July 9, 2021).

10. Howdeshell KL. A Model of the Development of the Brain as a Construct of the Thyroid System. Environ Health Perspect (2002) 110 Suppl 3:337-48. doi: 10.1289/ehp.02110s3337

11. Bernal J. Thyroid Hormones and Brain Development. Vitam Horm (2005) 71:95-122. doi: 10.1016/S0083-6729(05)71004-9

12. Pretell EA, Palacios P, Tello L, Wan M, Utiger RD, Stanbury JB. Iodine Deficiency and the Maternal/Fetal Relationship. In: Endemic Goiter and Cretinism Continuing Threats to World Health. Washington DC: PAHO (1974). p. 143-55.

13. Pretell EA, Caceres A. "Impairment of Mental Development by Iodine Deficiency and its Correction. A Retrospective View of Studies in Peru,", in: The Damaged Brain of Iodine Deficiency. New York, NY: Cognizant Communication. Available at: https://scholar.google.com/scholar_lookup? title=Impairment $\% 20$ of $\% 20$ mental $\% 20$ development $\% 20$ by $\% 20$ iodine $\%$ 20deficiency $\% 20$ and $\% 20$ its $\% 20$ correction. $\% 20 \mathrm{~A} \% 20$ retrospective $\% 20$ view $\%$ 20 of $\% 20$ studies $\% 20$ in $\% 20$ Peru\&author=EA \%20Pretell\&author $=\mathrm{A} \%$ 20Caceres\&author $=$ JB\%20Stanbury\&publication_year=1994\&book (Accessed July 11, 2021).

14. Jiskra J, Fait T, Bílek R, Krátký J, Bartáková J, Lukáš J, et al. Mild Iodine Deficiency in Women After Spontaneous Abortions Living in an IodineSufficient Area of Czech Republic: Prevalence and Impact on Reproductive Health. Clin Endocrinol (Oxf) (2014) 80:452-8. doi: 10.1111/cen.12298

15. Charoenratana $\mathrm{C}$, Leelapat $\mathrm{P}$, Traisrisilp K, Tongsong T. Maternal Iodine Insufficiency and Adverse Pregnancy Outcomes. Matern Child Nutr (2015) 12:680-7. doi: $10.1111 / \mathrm{mcn} .12211$

16. Abel MH, Caspersen IH, Sengpiel V, Jacobsson B, Meltzer HM, Magnus P, et al. Insufficient Maternal Iodine Intake Is Associated With Subfecundity, Reduced Foetal Growth, and Adverse Pregnancy Outcomes in the Norwegian Mother, Father and Child Cohort Study. BMC Med (2020) 18:211. doi: 10.1186/s12916-020-01676-w

17. Gargari SS, Fateh R, Bakhshali-Bakhtiari M, Saleh M, Mirzamoradi M, Bakhtiyari M. Maternal and Neonatal Outcomes and Determinants of Iodine Deficiency in Third Trimester of Pregnancy in an Iodine Sufficient
Area. BMC Pregnancy Childbirth (2020) 20:174. doi: 10.1186/s12884-02002863-6

18. Levie D, Korevaar TIM, Bath SC, Murcia M, Dineva M, Llop S, et al. Association of Maternal Iodine Status With Child IQ: A Meta-Analysis of Individual Participant Data. J Clin Endocrinol Metab (2019) 104:5957-67. doi: 10.1210/jc.2018-02559

19. Costeira MJ, Oliveira P, Santos NC, Ares S, Saenz-Rico B, de Escobar GM, et al. Psychomotor Development of Children From an Iodine-Deficient Region. J Pediatr (2011) 159:447-53. doi: 10.1016/j.jpeds.2011.02.034

20. Torlinska B, Bath SC, Janjua A, Boelaert K, Chan S-Y. Iodine Status During Pregnancy in a Region of Mild-to-Moderate Iodine Deficiency Is Not Associated With Adverse Obstetric Outcomes; Results From the Avon Longitudinal Study of Parents and Children (ALSPAC). Nutrients (2018) 10:29. doi: 10.3390/nu10030291

21. Ghassabian A, Steenweg-de Graaff J, Peeters RP, Ross HA, Jaddoe VW, Hofman A, et al. Maternal Urinary Iodine Concentration in Pregnancy and Children's Cognition: Results From a Population-Based Birth Cohort in an Iodine-Sufficient Area. BMJ Open (2014) 4:e005520. doi: 10.1136/bmjopen2014-005520

22. Nazeri P, Shariat M, Azizi F. Effects of Iodine Supplementation During Pregnancy on Pregnant Women and Their Offspring: A Systematic Review and Meta-Analysis of Trials Over the Past 3 Decades. Eur J Endocrinol (2021) 184:91-106. doi: 10.1530/EJE-20-0927

23. Dineva M, Fishpool H, Rayman MP, Mendis J, Bath SC. Systematic Review and Meta-Analysis of the Effects of Iodine Supplementation on Thyroid Function and Child Neurodevelopment in Mildly-to-Moderately IodineDeficient Pregnant Women. Am J Clin Nutr (2020) 112:389-412. doi: 10.1093/ajcn/nqaa071

Conflict of Interest: The author declares that the research was conducted in the absence of any commercial or financial relationships that could be construed as a potential conflict of interest.

Publisher's Note: All claims expressed in this article are solely those of the authors and do not necessarily represent those of their affiliated organizations, or those of the publisher, the editors and the reviewers. Any product that may be evaluated in this article, or claim that may be made by its manufacturer, is not guaranteed or endorsed by the publisher.

Copyright $(2021$ Lee. This is an open-access article distributed under the terms of the Creative Commons Attribution License (CC BY). The use, distribution or reproduction in other forums is permitted, provided the original author(s) and the copyright owner(s) are credited and that the original publication in this journal is cited, in accordance with accepted academic practice. No use, distribution or reproduction is permitted which does not comply with these terms. 